\title{
Measuring User Perspectives on Website Conference Using System Usability Scale
}

\section{Pengukuran Perspektif Pengguna Terhadap Website Conference Menggunakan System Usability Scale}

\author{
Nia Oktaviani ${ }^{1}$, Fatmasari ${ }^{2}$ \\ 1,2Information System Departement, Universitas Bina Darma, Palembang, Indonesia \\ Email: ${ }^{1}$ niaoktaviani@binadarma.ac.id, 2fatmasari@binadarma.ac.id
}

\begin{abstract}
Abstrak
Usability memiliki peranan yang amat begitu penting agar sebuah situs dapat bertahan, dengan usability yang tinggi maka sebuah website akan semakin banyak dikunjungi oleh pengguna internet. Untuk itu pada penelitian ini akan dilakukan pengukuran tingkat usability untuk mengetahui perspektif pengguna terhadap website conference Bina Darma Conference on Computer Science. Dalam melakukan pengukuran usability digunakan teknik pengukuran system usability scale. Penggunaan teknik ini karena pengukuran melibatkan pengguna akhir dari website atau dengan kata lain end user sebagai responden pengukuran. Alasan lain dilakukakannya pengukuran untuk melihat secara nyata tingkat partisipan pengguna $=$ dalam menggunakan website serta terdapat kendala-kendala yang muncul saat menggunakan website conference Bina Darma khususnya Bina Darma Conference on Computer Science. Hasil dari pengukuran menunjukkan bahwa pengguna atau responden memberikan nilai terhadap website conference Bina Darma Conference on Computer Science dapat digunakan dengan mudah yang dibuktikan dengan nilai yang diberkan responden mayoritas lebih dari 80 .
\end{abstract}

Kata Kunci: Usability, Website, System Usability Scale, BDCCS

\section{PENDAHULUAN}

Usability memiliki peranan yang penting agar sebuah situs dapat bertahan, dengan usability yang tinggi maka sebuah website akan semakin banyak dikunjungi oleh pengguna internet [1]. Usability merupakan aspek untuk mengukur seberapa mudah pengguna dalam mempelajari serta menggunakan produk untuk mencapai tujuannya serta tingkat kepuasan pengguna terhadap produk tersebut. Aspek ini juga dapat memberikan gambaran apakah tampilan dari sebuah website ini cocok dan disukai oleh penggunanya atau tidak [2]. Website saat ini telah digunakan diberbagai organisasi dengan tujuan mendukung kelancaran aktivitasnya. Organisasi yang menggunakan website tidak hanya pada dunia industri namun juga di dunia pendidikan. 
Universitas Bina Darma merupakan salah satu organisasi atau instansi pendidikan yang terletak di Provinsi Sumatra Selatan, saat ini Universitas Bina Darma memiliki berbagai website sebagai wadah penunjang kegiatan organisasi. Universitas Bina Darma memiliki berbagai website diantaranya website Online Journal system (OJS), website ini digunakan untuk mengeolah kegiatan seminar atau conference yang ada dilingkungan Universitas Bina Darma. Seminar atau conference tersebut yaitu: Bina Darma Conference on Psychology (BDCP), Prosiding Seminar Nasional Ekonomi dan Business Global Competitive Advantage, Bina Darma Conference on Computer Science (BDCCS), Bina Darma Conference on Engineering Science (BDCES), Seminar Nasional Teknologi Informasi dan Komunikasi (Semnastik), dan Seminar Hasil Penelitian Vokasi (Semhavok).

Saat ini dalam penggunaan website seminar atau conference di Universitas Bina Darma terdapat beberapa kendala yang dialami oleh pengguna, kendala yang muncul tersebut diantaranya Kurang lengkapnya nama kontributor pada fitur add contributor, banyak artikel yang di upload tidak sesuai dengan tempat, metadata yang tidak lengkap seperti abstract, serta additional refinements, sedikitnya partisipan yang upload artikel. Selain itu juga terdapat isu lain pada penggunaan website Bina Darama Conference on Computer science khususnya yaitu rendahnya partisipasi pengguna.

Rendahnya partisipasi pengguna dalam menggunakan website yang ada di Universitas Bina Darma terutama di Fakultas Ilmu Komputer tentunya menjadi isu penting. Kondisi tersebut terjadi mengingat website conference menjadi tulang punggung dalam pengelolaan conference. Untuk itu perlu diketahui bagaimana pandangan pengguna terhadap website conference agar terjadinya perbaikan. Untuk mengetahui bagaimana pandangan pengguna cara yang dapat dilakukan adalah dengan melakukan pengujian atau evaluasi. Salah satu teknik yang dapat digunakan adalah pengujian usability. Dalam melakukan pengujian Usability ada beberapa teknik pengukuran diantaranya heuristic evaluation (HE) dan system usability scale (SUS). Teknik heuristic evaluation (HE) merupakan metode penilaian yang bertujuan untuk memperbagus user experience, proses ini dilakukan oleh para ahli dengan upaya mendeteksi masalah yang ada pada fungsionalitas produk [3]. Sedangkan System Usability Scale (SUS) merupakan kuesioner yang digunakan untuk mengukur usability sistem komputer menurut sudut pandang subjektif pengguna [4]. Dari kedua teknik tersebut saya memilih teknik System Usability Scale (SUS), karena SUS mudah digunakan, dan tidak membutuhkan perhitungan yang rumit [3].

Sesuai dengan uraian yang telah dikemukakan, maka di dalam penelitian ini akan dilakukan evaluasi website conference terutama pada website conference Fakultas Ilmu Komputer. Hasil dari evaluasi atau pengukuran dapat digunakan sebagai langkah 
awal bahan perbaikan. Atas dasar hal tersebut, maka penulis mengambil judul penelitian "Analisis Kegunaan Website Conference Universitas Bina Darma dengan Teknik System Usability Scale". Diharapkan hasil penelitian ini menjadi dasar bagi perbaikan website conference yang ada di fakultas - fakultas lain.

\section{METODE PENELITIAN}

Metode penelitian yang digunakan pada penelitian ini berupa metode deskriptif. Penelitian Deskriptif merupakan penelitian yang ditujukan untuk memaparkan fenomena yang ada, baik fenomena alamiah maupun fenomena buatan manusia. Fenomena tersebut meliputi bentuk, aktivitas, perubahan, karakteristik, hubungan, kesamaan, serta perbedaan antara fenomena lainnya [5].

Dalam melakukan penelitian ini maka metode yang digunakan yaitu metode system usability scale (SUS). System usability scale (SUS) merupakan evaluasi usability yang melibatkan pengguna akhir (end user) dalam proses pelaksanaannya. Untuk itu jumlah responden yang berperan menjadi sangat penting untuk ditentukan. system usability scale (SUS) dalam menentukan responden tidak memiliki konsep yang baku atau tidak ada penentuan secara khusus dari teori dasarnya. Kondisi tersebut disebabkan responden dari system usability scale (SUS) merupakan pengguna akhir dari sebuah produk baik perangkat lunak maupun website. Dalam beberapa kajian menunjukkan system usability scale (SUS) menggunakan responden yang berbeda-beda bahkan sampai dengan empat ratus sembilan puluh sembilan responden [6]. Dalam pengujian yang lain juga ada yang menggunakan responden sangat sedikit yaitu lima dan sepulu responden [7]. Penggunaan jumlah responden yang berbeda merupakan independensi dan sesuai dengan kebutuhan peneliti itu sendiri. Seorang peneliti diberikan kebebasan dalam menentukan responden sesuai dengan rumusan atau teknik pengambilan sampel peneltian. System usability scale (SUS) memiliki aturan yang berbeda proses perhitungan hasil jawaban responden. Peberdaan tersebut terletak pada nomor ganjil dan genap instrumen pengujian [8], berikut adalah cara perhitungan hasil pengujian system usability scale (SUS):

a. Penyataan instrumen nomor ganjil skala jawaban instrumen dikurangi 1

b. Pernyataan instrumen nomor genap maka 5 dikurangi skala jawaban instrumen.

c. Hasil penilaian skala 0 - 4 (4 merupakan jawaban terbaik).

d. Melakukan penjumlahan jawaban kemudian dikali dengan 2.5

e. Menentukan nilai rerata jawaban instrumen pengujian semua responden Selanjutnya system usability scale (SUS) dalam menentukan hasil perhitungan

Penilaian terdapat tiga sudut pandang yaitu acceptability, grade scale, dan adjective rating. Acceptability terdapat tiga tingkatan yang terdiri dari not acceptable, marginal (rendah dan tinggi), dan acceptable. Sedangkan grade scale terdiri dari A, B, C, D dan 
Vol. 2, No. 2, September 2020

p-ISSN: 2656-5935 http://journal-isi.org/index.php/isi

e-ISSN: 2656-4882

F. Untuk adjective rating lebih banyak tingkatan yaitu worst imaginable, poor, ok, good, excellent dan best imaginable. Dari ketiga penilaian system usability scale (SUS) seperti yang diperlihatkan pada Gambar 1 bahwa acceptability digunakan untuk melihat tingkat penerimaan pengguna terhadap perangkat lunak, grade scale untuk melihat tingkatan (grade) website, dan adjective rating untuk melihat rating dari website yang dihasilkan. Selain dari ketiga cara tersebut system usability scale (SUS) memiliki cara lain dalam melakukan penentuan hasil peneilaian yaitu dengan cara SUS score percentile rank. Penentuan hasil penilaian berdasarkan SUS score percentile rank dilakukan secara umum berdasarkan hasil perhitungan penilaian pengguna. SUS score percentile rank memiliki perbedaan dengan acceptability, grade scale, adjective rating yang dikelompokkan menjadi tiga kategori. Berikut adalah ketentuan penentuan penilaian pada SUS score percentile rank [9], [10].

a. Grade A: dengan skor $>=80,3$

b. $\quad$ Grade B: dengan skor $>=74$ dan $<80,3$

c. Grade C: dengan skor $>=68$ dan $<74$.

d. Grade D: dengan skor $>=51$ dan $<68$.

e. $\quad$ Grade F: dengan skor lebih $<51$.

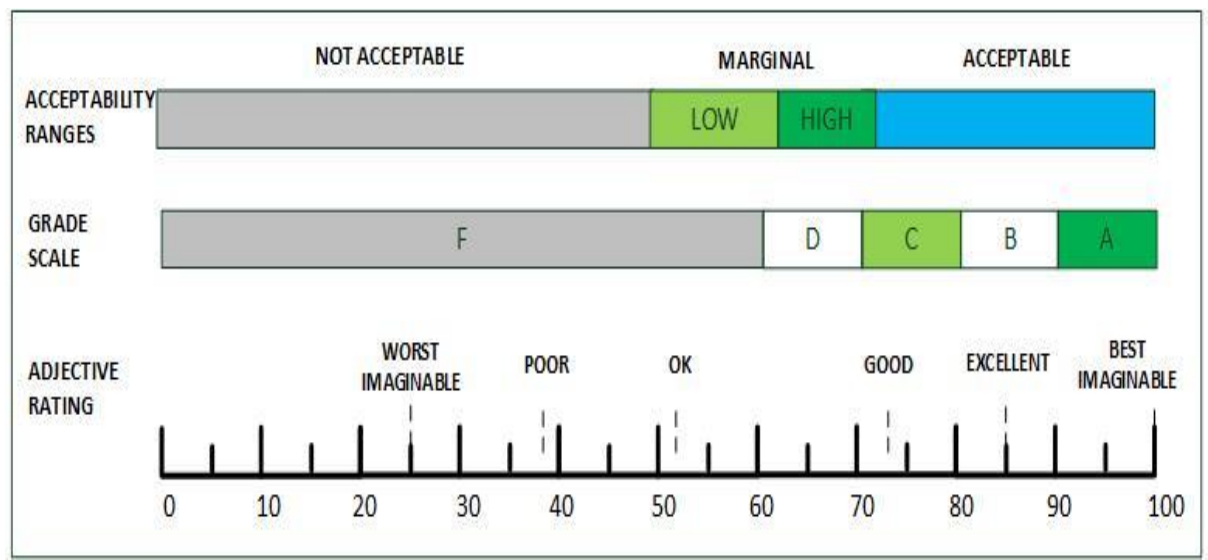

Gambar 1. Penilaian system usability scale [11]

Dalam melakukan proses evaluasi instrumen yang dimiliki system usability scale (SUS) terdapat sepuluh pernyataan yang menjadi tolak ukur pengujian. Instrumen pengujuian system usability scale (SUS) dapat digunakan untuk evaluasi bermacam jenis pengujian mulai dari website, sistem informasi dan perangkat lunak berbasis seluler [9]. Instrumen pengujian system usability scale (SUS) dapat dilihat pada Tabel 1. Seperti yang terlihat pada Tabel 1 dalam instrumen pengujian system usability scale (SUS) terdapat skala penilaian yang menjadi ukuran pembobotan ketika dilakukan pengujian. Skala penilaian tersebut diawali dengan 1 sampai dengan 5, 
Vol. 2, No. 2, September 2020

p-ISSN: 2656-5935 http://journal-isi.org/index.php/isi e-ISSN: 2656-4882

1 menunjukkan bahwa penguji sangat tidak setuju dengan pernyataan pengujian dan 5 sangat setuju terhadap pernyataan pengujian [12].

Tabel 1. Instrumen evaluasi system usability scale

\begin{tabular}{|c|c|c|}
\hline No & Pernyataan & Skala \\
\hline 1 & Saya akan ingin lebih sering mengunjungi website ini & $1-5$ \\
\hline 2 & Saya merasa website ini tidak harus dibuat serumit ini & $1-5$ \\
\hline 3 & Saya pikir website mudah untuk digunakan & $1-5$ \\
\hline 4 & $\begin{array}{l}\text { Saya membutuhkan bantuan dari orang teknis untuk } \\
\text { menggunakan website ini }\end{array}$ & $1-5$ \\
\hline 5 & Saya menemukan fitur pada website terintegrasi dengan baik & $1-5$ \\
\hline 6 & Saya pikir ada ketidaksesuaian dalam wesbite ini & $1-5$ \\
\hline 7 & $\begin{array}{l}\text { Saya merasa kebanyakan orang mudah untuk mempelajari } \\
\text { website dengan sangat cepat }\end{array}$ & $1-5$ \\
\hline 8 & Saya menemukan, website sangat rumit untuk digunakan & $1-5$ \\
\hline 9 & Saya percaya diri untuk menggunakan website ini & $1-5$ \\
\hline 10 & Saya perlu belajar sebelum saya menggunakan wesbite & $1-5$ \\
\hline
\end{tabular}

\section{HASIL DAN PEMBAHASAN}

\subsection{Karateristik Responden}

Berdasarkan intensitas pengunjung dalam penelitian ini, terdapat dosen Sistem Informasi dan Dosen Teknik Informatika yang berpartisipasi dalam Website Conference Universitas Bina Darma, yang di representasikan lewat Tabel 2 dibawah ini: 
Vol. 2, No. 2, September 2020

p-ISSN: 2656-5935 http://journal-isi.org/index.php/isi e-ISSN: 2656-4882

Tabel 2 Intensitas Pengunjung Website

\begin{tabular}{|l|c|c|}
\hline \multicolumn{1}{|c|}{ Intensitas Pengunjung } & Dosen SI & Dosen TI \\
\hline Sering & $40 \%$ & $50 \%$ \\
\hline Sesekali & $40 \%$ & $45 \%$ \\
\hline Pertama Kali & $20 \%$ & $5 \%$ \\
\hline Total & $\mathbf{1 0 0} \%$ & $\mathbf{1 0 0} \%$ \\
\hline
\end{tabular}

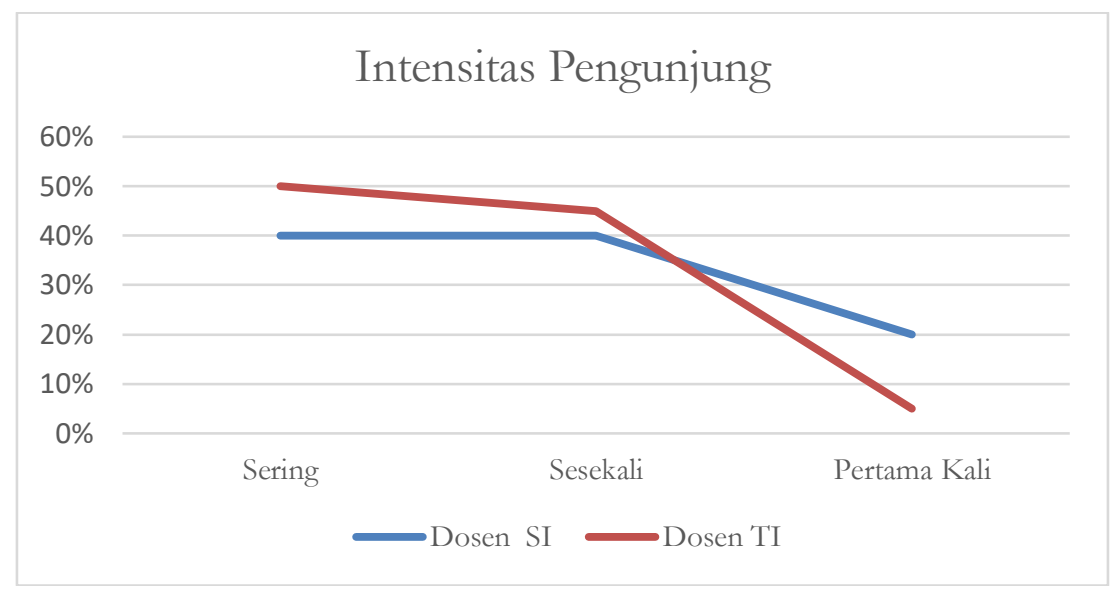

Gambar 2 Grafik Intensitas Pengunjung Website

Berdasarkan grafik intensitas pengunjung seperti yang diperlihatkan pada Gambar 2, terlihat bahwa responden dosen sistem informasi dan teknik informatika memiliki intensitas pengunjung yang tak jauh berbeda, dosen sistem informasi yang sering mengunjungi mencapai $40 \%$ dan dosen teknik informatika yang sering mengunjungi mencapai $50 \%$. Yang sesekali mengunjungi website untuk dosen sistem informasi mencapai $40 \%$ dan $45 \%$ untuk dosen teknik informatika, serta yang pertama kali mengunjungi website untuk dosen sistem informasi mencapai $20 \%$ dan $5 \%$ untuk dosen teknik informasika.

Selanjutnya adalah karateristik berdasarkan jenis kelamin, jumlah responden dalam penelitian ini yang berpartisipasi lebih banyak adalah perempuan dibanding laki-laki, dapat direpresentasikan lewat tabel 3 dibawah ini: 
Vol. 2, No. 2, September 2020

p-ISSN: 2656-5935 http://journal-isi.org/index.php/isi e-ISSN: 2656-4882

Tabel 3. Karateristik Jenis Kelamin

\begin{tabular}{|l|c|}
\hline \multicolumn{1}{|c|}{ Jenis Kelamin } & Persentase \\
\hline Laki-Laki & $40 \%$ \\
\hline Perempuan & $60 \%$ \\
\hline Jumlah & $\mathbf{1 0 0 \%}$ \\
\hline
\end{tabular}

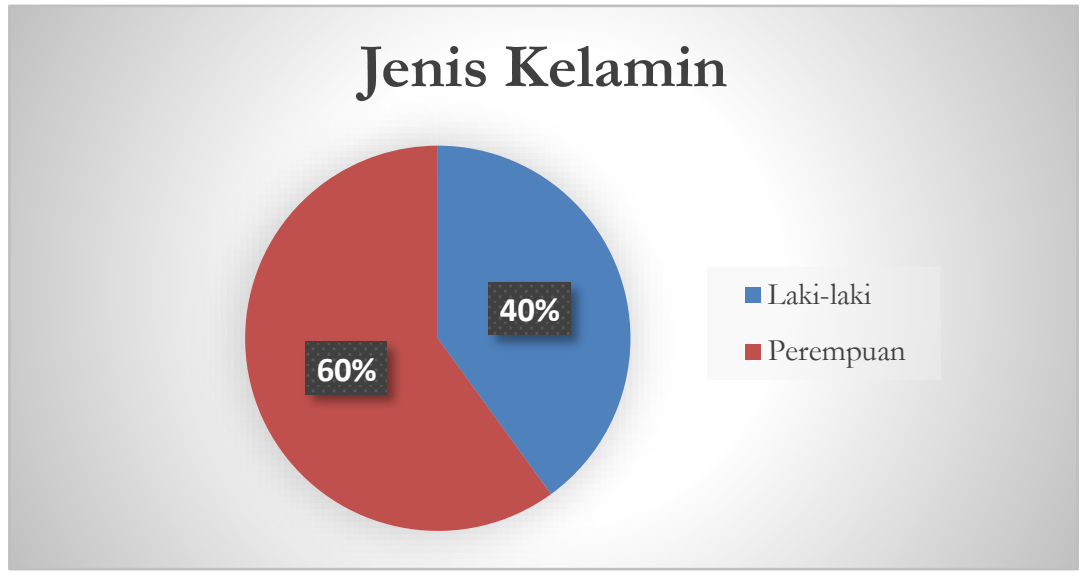

Gambar 3. Karateristik Jenis Kelamin Pengunjung Website

Berdasarkan diagram responden jenis kelamin diatas menunjukan bahwa, responden laki-laki sebesar $40 \%$ dan perempuan $60 \%$, hal ini menunjukan bahwa lebih banyak responden dosen perempuan dari pada dosen laki-laki. Berdasarkan program study yang telah merespon terdapat kesetaraan antara program study sistem informasi dan teknik informatika sebagaimana ditunjukkan pada Tabel 4 dibawah ini :

Tabel 4. Tabel Program Study

\begin{tabular}{|l|c|}
\hline \multicolumn{1}{|c|}{ Program Study } & Orang \\
\hline Dosen SI & 5 Orang \\
\hline Dosen TI & 5 Orang \\
\hline Jumlah & $\mathbf{1 0 ~ O r a n g}$ \\
\hline
\end{tabular}




\section{Program Studi}

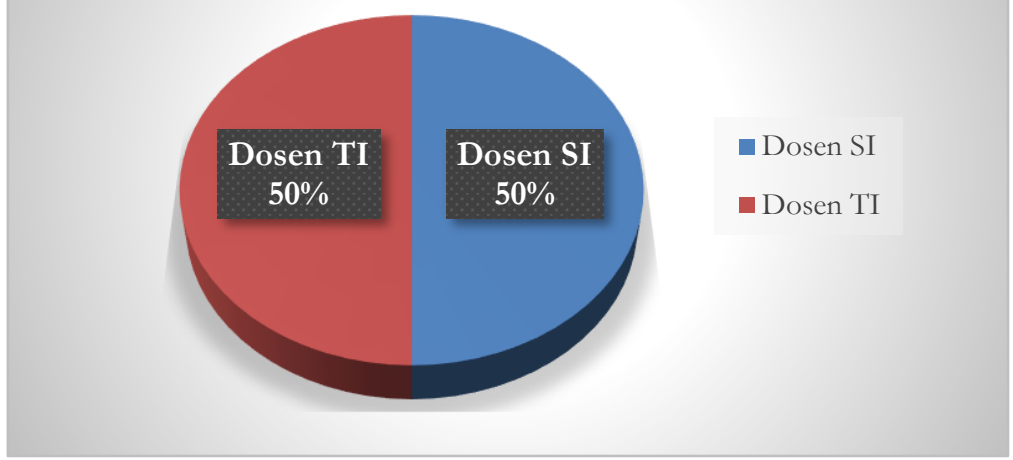

Gambar 4. Diagram Program Studi pengunjung Website

Berdasarkan diagram responden program study diatas, terdapat 10 responden yang telah berpartisipasi yaitu 5 orang dosen sistem informasi dan 5 orang dosen teknik informatika

\subsection{Hasil Penilaian}

Dari penilaian responden terhadap website Bina Darma Conference on Computer Science dapat dijelaskan untuk masing-masing pernyataan seabgai berikut. Pernyataan pertama berbunyi "Saya akan ingin lebih sering mengunjungi website ini" dari pernyataan ini responden pertama menjawab skala 5, responden kedua menjawab skala 5, responden ketiga menjawab skala 4, responden keempat menjawab dengan skala 4, responden kelima menjawab dengan skala 5, responden keenam menjawab dengan skala 4, reponden ketujuh menjawab dengan skala 5, responden kedelapan menjawab dengan skala 4, responden kesembilan menjawab dengan skala 4, responden kesepuluh menjawab dengan skala 4. Dari keseluruhan responden menjawab rata-rata diskala 4 dan 5 menunjukan bahwa responden mempunyai antusias yang baik terhadap website Bina Darma Conference on Computer Science.

Pernyataan kedua berbunyi "Saya merasa website ini tidak harus dibuat serumit ini" dari pernyataan ini responden pertama menjawab skala 1, responden kedua menjawab skala 2, responden ketiga menjawab skala 3, responden keempat menjawab dengan skala 2, responden kelima menjawab dengan skala 2, responden keenam menjawab dengan skala 2, reponden ketujuh menjawab dengan skala 1,responden kedelapan menjawab dengan skala 1, responden kesembilan menjawab dengan skala 1 , responden kesepuluh menjawab dengan 
skala 3. Dapat dikatakan bahwa responden tidak setuju dengan adanya pernyataan ini, karena tidak ada yang rumit di website coference ini.

Pernyataan ketiga berbunyi "Saya pikir website mudah untuk digunakan" dari pernyataan ini responden pertama menjawab skala 4, responden kedua menjawab skala 4, responden ketiga menjawab skala 4, responden keempat menjawab dengan skala 4, responden kelima menjawab dengan skala 5, responden keenam menjawab dengan skala 4, reponden ketujuh menjawab dengan skala 4,responden kedelapan menjawab dengan skala 5, responden kesembilan menjawab dengan skala 5, responden kesepuluh menjawab dengan skala 4. Dari keseluruhan responden menjawab rata-rata diskala 4 dan 5 , menunjukan bahwa responden setuju dengan pernyataan ini dan memang website conference mudah untuk digunakan.

Pernyataan keempat berbunyi "Saya membutuhkan bantuan dari orang teknis untuk menggunakan website ini" dari pernyataan ini responden pertama menjawab skala 2, responden kedua menjawab skala 2, responden ketiga menjawab skala 2 , responden keempat menjawab dengan skala 1 , responden kelima menjawab dengan skala 1, responden keenam menjawab dengan skala 1, reponden ketujuh menjawab dengan skala 1 , responden kedelapan menjawab dengan skala 1, responden kesembilan menjawab dengan skala 1, responden kesepuluh menjawab dengan skala 2. Dapat dilihat dari jawaban responden yang rata-rata menjawab skala 1 dan 4, dapat dikatakan bahwa responden tidak setuju dengan pernyataan ini, karena tidak dibutuhkannya bantuan orang teknis untuk menggunakan website ini karena website sudah dirancang sebagamaina mestinya.

Pernyataan kelima berbunyi "Saya menemukan fitur pada website terintegrasi dengan baik" dari pernyataan ini responden pertama menjawab skala 5, responden kedua menjawab skala 5, responden ketiga menjawab skala 5, responden keempat menjawab dengan skala 5, responden kelima menjawab dengan skala 5 , responden keenam menjawab dengan skala 5 , reponden ketujuh menjawab dengan skala 5 , responden kedelapan menjawab dengan skala 5, responden kesembilan menjawab dengan skala 5, responden kesepuluh menjawab dengan skala 5. Dapat dilihat dari jawaban responden yang semuanya menjawab skala 5, dapat disimpulkan semua responden setuju dengan terintegrasinya website dengan baik.

Pernyataan keenam berbunyi "Saya pikir ada ketidaksesuaian dalam wesbite ini" dari pernyataan ini responden pertama menjawab skala 2, responden kedua menjawab skala 2, responden ketiga menjawab skala 2, responden keempat menjawab dengan skala 1 , responden kelima menjawab dengan skala 2, responden keenam menjawab dengan skala 2, reponden ketujuh menjawab dengan skala 2, responden kedelapan menjawab dengan skala 2, responden kesembilan menjawab dengan skala 2, responden kesepuluh menjawab dengan skala 2. Rata-rata responden menjawab skala 2 dan 1 dapat dikatakan bahwa tidak adanya ketidaksesuaian dalam website conference ini. 
Pernyataan ketujuh berbunyi "Saya merasa kebanyakan orang mudah untuk mempelajari website dengan sangat cepat" dari pernyataan ini responden pertama menjawab skala 5, responden kedua menjawab skala 5, responden ketiga menjawab skala 5, responden keempat menjawab dengan skala 4, responden kelima menjawab dengan skala 4, responden keenam menjawab dengan skala 4, reponden ketujuh menjawab dengan skala 5, responden kedelapan menjawab dengan skala 4, responden kesembilan menjawab dengan skala 5, responden kesepuluh menjawab dengan skala 5. Dilihat dari responden menjawab rata-rata skala 5 dan 4, dapat disimpulkan bahwa responden mudah untuk mempelajari website dengan sangat cepat.

Pernyataan kedelapan berbunyi "Saya menemukan, website sangat rumit untuk digunakan" dari pernyataan ini responden pertama menjawab skala 1 , responden kedua menjawab skala 1 , responden ketiga menjawab skala 1 , responden keempat menjawab dengan skala 1, responden kelima menjawab dengan skala 2, responden keenam menjawab dengan skala 2, reponden ketujuh menjawab dengan skala 2, responden kedelapan menjawab dengan skala 1, responden kesembilan menjawab dengan skala 1 , responden kesepuluh menjawab dengan skala 1. Dilihat dari jawaban responden yang rata-rata menjawab skala 1 dan 2, dapat disimpulkan bahwa website tidak begitu rumit dalam proses pengerjaannya.

Pernyataan kesembilan berbunyi "Saya percaya diri untuk menggunakan website ini" dari pernyataan ini responden pertama menjawab skala 4, responden kedua menjawab skala 4, responden ketiga menjawab skala 4, responden keempat menjawab dengan skala 4, responden kelima menjawab dengan skala 5, responden keenam menjawab dengan skala 4, reponden ketujuh menjawab dengan skala 5, responden kedelapan menjawab dengan skala 4, responden kesembilan menjawab dengan skala 5, responden kesepuluh menjawab dengan skala 4. Dari keseluruhan responden yang rata-rata menjawab skala 4 dan 5 , disimpulkan bahwa responden percaya diri dalam melakukan ataupun menggunakan website ini.

Pernyataan kesepuluh berbunyi "Saya perlu belajar sebelum saya menggunakan wesbite" dari pernyataan ini responden pertama menjawab skala 2 , responden kedua menjawab skala 2, responden ketiga menjawab skala 3, responden keempat menjawab dengan skala 3, responden kelima menjawab dengan skala 2, responden keenam menjawab dengan skala 2, reponden ketujuh menjawab dengan skala 2, responden kedelapan menjawab dengan skala 2, responden kesembilan menjawab dengan skala 2, responden kesepuluh menjawab dengan skala 3. Beragam jawaban dari responden yang menjawab skala 1,2,dan3 dapat disimpulkan bahwa sebagian responden perlu belajar dalam melakukan proses pekerjaan melalui website dan sisanya sudah mengetahui dalam menggunakan website ini. 
Vol. 2, No. 2, September 2020

p-ISSN: 2656-5935

http://journal-isi.org/index.php/isi

e-ISSN: 2656-4882

Selanjutnya menentukan grade hasil penilaian, ada 2 cara yang dapat digunakan untuk mendapatkan grade hasil penilaian, Penentuan pertama dilihat dari sisi tingkat penerimaan pengguna, grade skala dan adjektif rating yang terdiri dari tingkat penerimaan, penentuan yang kedua dilihat dari sisi percentile range (SUS skor) yang memiliki grade penilaian yang terdiri dari A, B, C, D dan F. Hasil rekapitulasi penilaian seluruh responden setelah diolah dapat dilihat pada Tabel 5 dibawah ini.

Tabel 5. Tabel Jawaban Setelah diolah dengan SUS

\begin{tabular}{|c|c|c|c|c|c|c|c|c|c|c|c|c|}
\hline \multirow{2}{*}{ Responden } & \multicolumn{10}{|c|}{ Jawaban Responden } & \multirow{2}{*}{ JUMLAH } & \multirow{2}{*}{ NILAI R } \\
\hline & P1 & P2 & P3 & P4 & P5 & P6 & P7 & P8 & $\mathrm{Pg}$ & $\mathrm{P} 10$ & & \\
\hline R1 & 4 & 4 & 3 & 3 & 4 & 3 & 4 & 4 & 3 & 3 & 35 & 87,5 \\
\hline R2 & 4 & 3 & 3 & 3 & 4 & 3 & 4 & 4 & 3 & 3 & 34 & 85 \\
\hline R3 & 3 & 2 & 3 & 3 & 4 & 3 & 4 & 4 & 3 & 2 & 31 & 77,5 \\
\hline R4 & 3 & 3 & 3 & 4 & 4 & 4 & 3 & 4 & 3 & 2 & 33 & 82,5 \\
\hline R5 & 4 & 3 & 4 & 4 & 4 & 3 & 3 & 3 & 4 & 3 & 35 & 87,5 \\
\hline R6 & 3 & 3 & 3 & 4 & 4 & 3 & 3 & 3 & 3 & 3 & 32 & 80 \\
\hline R7 & 4 & 4 & 3 & 4 & 4 & 3 & 4 & 3 & 4 & 3 & 36 & 90 \\
\hline R8 & 3 & 4 & 4 & 4 & 4 & 3 & 3 & 4 & 3 & 4 & 36 & 90 \\
\hline Rg & 3 & 4 & 4 & 4 & 4 & 3 & 4 & 4 & 4 & 3 & 37 & 92,5 \\
\hline R10 & 3 & 2 & 3 & 3 & 4 & 3 & 4 & 4 & 3 & 2 & 31 & 77,5 \\
\hline
\end{tabular}

Responden pertama mendapatkan hasil 87,5 yang menyatakan grade A yang berarti sangat baik, responden kedua mendapatkan hasil 85 yang menyatakan grade A yang berarti sangat baik, responden ketiga mendapatkan hasil 77,5 yang menyatakan grade B yang berarti baik, responden keempat mendapatkan hasil 82,5 yang menyatakan grade A yang berarti sangat baik, responden kelima mendapatkan hasil 87,5 yang menyatakan grade A yang berarti sangat baik, responden keenam mendapatkan hasil 80 yang menyatakan grade B yang berarti baik, responden ketujuh mendapatkan hasil 90 yang menyatakan grade A yang berarti sangat baik, responden kedelapan mendapatkan hasil 90 yang menyatakan grade A yang berarti sangat baik, responden kesembilan mendapatkan hasil 92,5 yang menyatakan grade A yang berarti sangat baik, responden kesepuluh mendapatkan hasil 77,5 yang menyatakan grade B yang berarti baik.

\section{KESIMPULAN}

Dari hasil penelian yang diberikan terhadap website Bina Darma Conference on Computer Science maka dapat disimpulkan bawah: (1) Adjective Rating digunakan untuk melihat sejauh mana perspective pengguna terhadap Website Conference Universitas Bina Darma Untuk menentukan Acceptability, scale, adjective rating maka dilakukan perbandingan hasil, penilaian rata-rata responden mendapatkan hasil akhir sebesar 85 yang berada pada grade A dengan ketentuan seperti gambar penilaian sesuai dengan Gambar 1. (2) Website Conference Universitas Bina Darma 
dapat digunakan dengan mudah oleh pengguna untuk mendapatkan layanan informasi yang dibuktikan dengan nilai yang diberkan responden mayoritas lebih dari 80. (3) System Usability Scale yang digunakan sebagai bahan evaluasi website conference mendapatkan hasil yang memberi dampak baik terhadap website Bina Darma Conference on Computer Science.

\section{REFERENSI}

[1] I. Salamah, "Evaluasi Usability Website Polsri Dengan Menggunakan System Usability Scale," J. Nas. Pendidik. Tek. Inform. JANAPATI, vol. 8, no. 3, 2020.

[2] A. W. Soejono, A. Setyanto, and A. F. Sofyan, "Evaluasi Usability Website UNRIYO Menggunakan System Usability Scale (Studi Kasus: Website UNRIYO)," Respati, vol. 13, no. 1, 2018.

[3] U. Ependi, T. B. Kurniawan, and F. Panjaitan, "System Usability Scale Vs Heuristic Evaluation: A REVIEW," Simetris J. Tek. Mesin, Elektro dan Ilmu Komput., vol. 10, no. 1, pp. 65-74, 2019.

[4] L. D. Setia, "Evaluasi Usability Untuk Mengetahui Akseptabilitas Aplikasi Berbasis Web," MULTITEK Indones., vol. 6, no. 1, pp. 41-48, 2012.

[5] U. Ependi, F. Panjaitan, and H. Hutrianto, "System Usability Scale Antarmuka Palembang Guide Sebagai Media Pendukung Asian Games XVIII," J. Inf. Syst. Eng. Bus. Intell., vol. 3, no. 2, pp. 80-86, 2017.

[6] P. T. Kortum and A. Bangor, "Usability ratings for everyday products measured with the System Usability Scale," Int. J. Hum. Comput. Interact., vol. 29, no. 2, pp. 67-76, 2013.

[7] B. Pudjoatmodjo and R. Wijaya, "Tes Kegunaan (Usabilty Testing) Pada Aplikasi Kepegawaian Dengan Menggunakan System Usabilty Scale (Studi Kasus: Dinas Pertanian Kabupaten Bandung)," SEMNASTEKNOMEDIA ONLINE, vol. 4, no. 1, pp. 2-9, 2016.

[8] F. P. Juniawan and D. Y. Sylfania, "Usability Evaluation of AndroidBased Lecturer Research Publication Reporting System," J. RESTI (Rekayasa Sist. dan Teknol. Informasi), vol. 4, no. 1, pp. 123-134, 2020.

[9] J. Sauro, A practical guide to the system usability scale: Background, benchmarks \& best practices. Measuring Usability LLC, 2011.

[10] A. Bangor, P. Kortum, and J. Miller, "Determining what individual SUS scores mean: Adding an adjective rating scale," J. usability Stud., vol. 4, no. 3, pp. 114-123, 2009.

[11] T. S. Tullis and J. N. Stetson, "A comparison of questionnaires for assessing website usability," in Usability professional association conference, 2004, vol. 1.

[12] J. Brooke, "SUS-A quick and dirty usability scale," Usability Eval. Ind., vol. 189, no. 194, pp. 4-7, 1996. 